This item is the archived peer-reviewed author-version of:

Freight transport models : ready to support transport policy of the future?

\title{
Reference:
}

Meersman Hilde, Van de Voorde Eddy.- Freight transport models : ready to support transport policy of the future?

Transport policy - ISSN 0967-070X - 83(2019), p. 97-101

Full text (Publisher's DOI): https://doi.org/10.1016/J.TRANPOL.2019.01.014

To cite this reference: https://hdl.handle.net/10067/1648360151162165141 
Topical paper

\section{FREIGHT TRANSPORT MODELS: READY TO SUPPORT TRANSPORT POLICY OF THE FUTURE?}

Hilde Meersman University of Antwerp, Prinsstraat 13, 2000 Antwerpen, Belgium, hilde.meersman@uantwerpen.be

Eddy Van de Voorde University of Antwerp, Prinsstraat 13, 2000 Antwerpen, Belgium, eddy.vandevoorde@uantwerpen.be

Corresponding author:

Hilde Meersman

University of Antwerp, CST

Prinsstraat 13

2000 Antwerpen

Belgium

hilde.meersman@uantwerpen.be 


\title{
Topical paper
}

\section{FREIGHT TRANSPORT MODELS: READY TO SUPPORT TRANSPORT POLICY OF THE FUTURE?}

\begin{abstract}
The traditional model-based approach is no longer capable of grasping developments in freight transport within an ever more rapidly changing world. Most models that have been used in the past to explain and predict the demand for freight transport did not devote sufficient consideration to structural, organisational and behavioural changes. Several important global developments that are taking place could have a structural effect on freight transport, with a number of consequences for modelling. This paper addresses several global developments in greater depth, along with their impact on freight transport. This is followed by a discussion of the future of freight models. It is unclear which approach would be appropriate for freight transport under these conditions. This is a clear problem that is linked to a research agenda.
\end{abstract}

Keywords: Freight, Modelling, Future

\section{Background}

Governments have used transport models to a greater or lesser extent to support their transport policy. After the Second World War, transport policy focused primarily on stimulating mobility in order to support economic recovery and growth. There was a particular need for investments in infrastructure and in transport networks. This meant that special attention was paid to models that were able to calculate forecasts and evolutions of the transport demand.The majority of these models had been designed for passenger transport, with many fewer models for freight transport.

Demand for transport continued to increase in the period 1970-2000, as a result of globalisation and global economic growth. Even with further infrastructure expansion, the capacity was no longer sufficient in some places and at some times. There was a need for short-term planning and improvements in the productivity and efficiency of the transport system. In addition to models of the demand for transport, more attention was now being paid to the supply side and the transport operators. For freight transport, the attention increasingly shifted to the planning and management of the logistics chain.

The persistent growth of transport also led to a pronounced increase in negative external effects. The sustainability of transport in all of its aspects thus became one of the major points of attention in policy. In 2014, the GHG emissions of transport in the EU28 were still $20 \%$ higher than they had been in 1990, while clear decreases could be observed in all other sectors (EEA, Eurostat, 2016). On the global scale, direct GHG emissions increased by $250 \%$ from 1970 to 2010 . The greatest share could be attributed to the large and increasing share of road transport (IPCC, 2014). Freight transport contributes a share of approximately $30 \%$ of total GHG emissions, primarily due to the increasing emissions of freight transport over roadways. 
Notwithstanding the major progress that has been made in technology and in transport modelling, no success has been achieved in limiting and reducing the negative external effects of transport. One reason is that most models that have been used in the past to explain and predict the demand for freight transport did not devote sufficient consideration to structural, organisational and behavioural changes. It is therefore no surprise that problems have emerged in forecasting and that estimates of developments in freight transport have been wrong in many cases.

The traditional model-based approach is no longer capable of grasping developments in freight transport within an ever more rapidly changing world. For example, what is the effect of a reversal in the flow of goods on the organisation of transport and the use of the infrastructure? What are the consequences of bubbles, including those resulting from a demand for raw materials that are or are not influenced by speculation? One has to deal with structural shifts, that is system changes with a major impact on the transport system and/or the handling of freight transport . 'Business as usual' no longer applies.

Moreover, policy design and implementation are dynamic processes that are subject to many uncertainties and time lags. The delays involved in recognising a disturbance, deciding to act and feeling the final impacts of policy measures are of differing natures. The length of the recognition lag depends upon a number of factors, and it can be substantially reduced if the disturbance can be predicted. Models and other forecasting tools can be of considerable assistance in reducing the recognition lag. The decision lag is determined largely by the decision process. Political and legal procedures can extend this process, although adequate preparation based on good forecasting can raise awareness and shorten the decision process in this regard. Finally, the action lag depends on the nature of the actions to be taken and their implementation process. For example, it takes considerably more time to build a new railroad than it does to increase fuel taxes.

One major problem is that, during the period between the recognition of a problem and the final implementation of the policy, the world keeps turning and, more directly, the primary reactions of the agents affected by such policies will are followed by the secondary reactions of other agents, and so on. One consequence could be that, by the time a policy is finally implemented, the problems are likely to have changed considerably, such that the policy is no longer optimal. In the most extreme case, the policy actions may no longer be suitable for the new situation.

This can be avoided by designing policies in a dynamic manner and ensuring a proper monitoring process for keeping track of the development of problems over time, along with the policies and the transport system. Such solutions require a thorough knowledge of dynamic modelling of the interactions within the transport sector, as well as of such aspects as the behaviour of policy-makers and the agents in the transport field, the relationship between the transport sector and other relevant sectors and the impact of policy actions.

This paper addresses several global developments in greater depth, along with their impact on freight transport. This is followed by a discussion of the future of freight models. It is unclear which approach would be appropriate for freight transport under these conditions. This is a clear problem that could be linked to a research agenda. 


\section{Global developments and their impact on freight transport}

Freight transport demand remains largely a derived demand, and is therefore linked to the scope and structure of economic activity. It would nevertheless be wrong to assume that the intensity of this link does not change. The organisation of global economic activity and the supply chains - which may or may not be influenced by policy measures - together determine the course of freight flows.

Most of the existing freight models are still constructed according to the four- or five-step method, possibly with the application of more advanced techniques, refinements and better datasets. They nevertheless continue to have problems coping with the structural changes and uncertainties with which our world is being confronted. This makes it difficult to design policies for sustainable freight transport using the existing freight models.

Several important global developments that are taking place could have a structural effect on freight transport, with a number of consequences for modelling. A typology of important developments and their effects on the transport system is presented in Table 1 . The global developments presented here can be subdivided into several categories, based on the driver: evolutions in the commodities and energy markets, political decisions, changes in market conditions and exogenous developments. Each of these developments involves problems that could generate a structural effect in the long term. It is currently unclear whether even more of these breaks with the past are lurking around the corner, what their possible consequences could be and how the actors are likely to react to them.

Table 1 Important global developments and their effects on the freight transport system

\begin{tabular}{|c|c|}
\hline Important global developments & Structural effects on the transport system \\
\hline \multicolumn{2}{|l|}{ Commodities and energy markets } \\
\hline $\begin{array}{l}\text { Developments in the oil and energy sector } \\
\text { (e.g. strong volatility in crude oil process, } \\
\text { emergence of shale gas and other energy } \\
\text { sources) }\end{array}$ & $\begin{array}{l}\text { - Strong fluctuations in the transport of crude } \\
\text { oil } \\
\text { - Major impact on production processes and } \\
\text { the trade and use of fuels } \\
\text { - Use of alternative fuels (e.g. LNG as bunker) } \\
\text { - Adaptations in engines and the design of } \\
\text { lorries, aircrafts and ships }\end{array}$ \\
\hline $\begin{array}{l}\text { Very strong price fluctuations for raw } \\
\text { materials, partly due to speculation (cf. } \\
\text { bubbles) }\end{array}$ & $\begin{array}{l}\text { - Strong changes in the demand for the } \\
\text { transport of raw materials, linked to the } \\
\text { building up/depletion of supplies } \\
\text { - Strong fluctuations in transport capacity, with } \\
\text { periods of extremely high overcapacity }\end{array}$ \\
\hline $\begin{array}{l}\text { New sources for the extraction of raw } \\
\text { materials }\end{array}$ & $\begin{array}{l}\text { - Different ports of loading and shipping routes } \\
\text { - Effect on distance, and thus on the tonne- } \\
\text { miles realised }\end{array}$ \\
\hline $\begin{array}{l}\text { Shift from raw-material exporting countries to } \\
\text { importing countries }\end{array}$ & $\begin{array}{l}\text { - Technology for loading and unloading (e.g. } \\
\text { coal) is often completely different, and } \\
\text { adaptation requires major investments }\end{array}$ \\
\hline $\begin{array}{l}\text { Use of new materials in industry, construction, } \\
\text { transport and other sectors }\end{array}$ & $\begin{array}{l}\text { - Imposition of other requirements on } \\
\text { transport }\end{array}$ \\
\hline
\end{tabular}




\begin{tabular}{|c|c|}
\hline & $\begin{array}{l}\text { - Changes in efficiency and productivity within } \\
\text { the transport sector }\end{array}$ \\
\hline \multicolumn{2}{|l|}{ Political decisions } \\
\hline $\begin{array}{l}\text { Geo-political changes, transition between } \\
\text { political systems, changes in national and } \\
\text { international trade politics }\end{array}$ & $\begin{array}{l}\text { - Changes in trade volumes and thus in } \\
\text { transport flows }\end{array}$ \\
\hline $\begin{array}{l}\text { Deregulation/privatisation/re-regulation of } \\
\text { the transport system }\end{array}$ & $\begin{array}{l}\text { - Effect on productivity, market balance and } \\
\text { thus price levels }\end{array}$ \\
\hline $\begin{array}{l}\text { Increased security in response to the threat of } \\
\text { terrorism and piracy }\end{array}$ & $\begin{array}{l}\text { - Built-in safety thresholds in the settlement of } \\
\text { logistical flows (e.g. container scanning) }\end{array}$ \\
\hline \multicolumn{2}{|l|}{ Changes in market conditions } \\
\hline Periods of exceptional overcapacity & $\begin{array}{l}\text { - Collapse of price levels (e.g. in European } \\
\text { inland waterway transport, as a result of } \\
\text { decimation) }\end{array}$ \\
\hline $\begin{array}{l}\text { Relocation of the 'processing plant' and global } \\
\text { value chain, thereby changing trade patterns }\end{array}$ & $\begin{array}{l}\text { - Changed logistics chain settlement } \\
\text { - Different ports of unloading and shipping } \\
\text { routes } \\
\text { - Effect on distance and tonne-miles realised }\end{array}$ \\
\hline $\begin{array}{l}\text { Mergers and acquisitions in the transport } \\
\text { sector }\end{array}$ & $\begin{array}{l}\text { - Horizontal and vertical integration } \\
\text { - Scale increase } \\
\text { - Oligopolistic markets }\end{array}$ \\
\hline $\begin{array}{l}\text { Changes in the demand for finished or semi- } \\
\text { finished products (e.g. trade in crude oil, } \\
\text { influenced by the market for hydrogen or } \\
\text { other forms of energy) }\end{array}$ & $\begin{array}{l}\text { - Changes in export and import volumes } \\
\text { - Changes in trade flows }\end{array}$ \\
\hline \multicolumn{2}{|l|}{ Exogenous developments } \\
\hline $\begin{array}{l}\text { Socio-demographic developments with } \\
\text { changing consumption patterns }\end{array}$ & $\begin{array}{l}\text { - Impact on transport flows } \\
\text { - Attention to healthcare logistics }\end{array}$ \\
\hline $\begin{array}{l}\text { Climate change and imposed reductions in } \\
\text { greenhouse gases }\end{array}$ & $\begin{array}{l}\text { - Reductions in transport volume due to either } \\
\text { direct regulations or price mechanisms } \\
\text { - New navigable routes (e.g. Northern Passage) }\end{array}$ \\
\hline $\begin{array}{l}\text { Important new infrastructure or expanded } \\
\text { infrastructure (e.g. Panama Canal, Maasvlakte } \\
2 \text { in the Port of Rotterdam) }\end{array}$ & $\begin{array}{l}\text { - Impact on cost and price setting } \\
\text { - Changing competition }\end{array}$ \\
\hline $\begin{array}{l}\text { Technology: } \\
\text { - New and/or adapted transport technology } \\
\text { and systems } \\
\text { - E-commerce, internet of things }\end{array}$ & $\begin{array}{l}\text { - Increased efficiency and productivity } \\
\text { - Impact on cost and price setting } \\
\text { - Changing organisation of logistics chains }\end{array}$ \\
\hline Urbanisation & $\begin{array}{l}\text { - Changing urban distribution systems } \\
\text { - Increasing importance of last-mile and waste } \\
\text { logistics }\end{array}$ \\
\hline
\end{tabular}

Original composition

As shown in Table 1, the various developments often amount to the same consequences for the transport system: strong changes in the volume, composition and direction of transport flows, including those involving new transport routes; new technologies; strong changes in the cost structure; new markets and market conditions; and wider price fluctuations. 
These developments have far-reaching consequences for the models that are used, and these consequences should not be ignored. Basic data from the transport matrices do not provide a proper indication of the drastically changing situations, such that traditional transport models (e.g. the four/five-step model) are no longer usable. In other cases, previously estimated coefficients such as the elasticities reflecting the price and cost sensitivities of the various decision-makers are no longer usable, as they were estimated under conditions with only minor fluctuations in prices and costs, and they did not consider behavioural changes under the influence of large fluctuations and volatility.

In the past, decisions were often taken based on the existing situation and the traditional models. Reactions to new developments, a changed business environment and structural changes were either absent or late. As a consequence, politicians and corporate leaders might lose faith in traditional transport models that over- or underestimated the consequences of their policy measures. However, a model-based approach would still seem possible, even for an environment with structural breaks. It merely requires the courage to think outside the box when designing the freight models of the future.

\section{The future of freight models}

Most existing methods and models have difficulty coping with structural changes and the uncertainties with which we are confronted. The fundamental problem is that they assume that the characteristics of the agents and the flows in the transport system (e.g. logistics, market structures, spatial organisation, perceptions, trade patterns) will remain largely unchanged. This makes it hard to come to reliable estimates of the impact of policy, regulations and the demand for transport, particularly in the long term. In the field of macro-economic policy, the Lucas Critique already argued that it would be naive to try to predict the effects of a change in economic policy based purely on the observed relationships revealed in historical and often aggregated data series. ${ }^{1}$ Economic agents have rational expectations and will adjust their behaviour in function of government-policy measures based on models that assumed stable behaviour. As a consequence their reactions no longer correspond to the pattern of expectations that policy-makers had formed for themselves based on existing economic models. ${ }^{2}$

In recent decades, the modelling of freight transport has evolved from a non-structural, aggregated engineering approach (e.g. focusing on routing decisions) towards a structural, disaggregated approach. The aggregated models used global data on shippers and shipments, with the goal of identifying general relationships linked to underlying behavioural assumptions. More sophisticated

\footnotetext{
${ }^{1}$ '[G]iven that the structure of an econometric model consists of optimal decision rules of economic agents, and that optimal decision rules vary systematically with changes in the structure of series relevant to the decision maker, it follows that any changes in policy will systematically alter the structure of econometric models.' (Lucas, 1976, p. 41)

2 Boland (2014, p. 40) writes the following in this regard: "However, in "new Keynesian" macroeconomic theoretical models, the relationship (or the "deep parameters" that characterize the relationships with regard to tastes and technology) are usually presumed not to change over the relevant time-period - the presumption that the Lucas Critique challenged. The entire explanation of historical change is usually invested in the exogenous changes of the givens and sometimes only in external shocks'.
} 
models make use of flexible functional forms, in which traditional restrictions such as homogeneity, economies of scale, and separability can be tested. With a combination of new empirical methods and increased availability of detailed shipment and company-level data, freight transport models have evolved towards analyses that are more behavioural and disaggregated in nature (Ben-Akiva et al, 2013, p. 4).

Changes in the transport sector that give rise to system changes often render existing models and estimated coefficients unusable. The traditional and relatively mechanical approach, which fully responds to the derived character of the demand for transport and which often relies on the use of transport matrices (cf. the four/five-step model), no longer works.

A possible alternative involves the detailed analysis and modelling of the decision processes of the various actors involved in transport. One approach is the Principal Agent theory: a relationship in which a principal (client) contracts with an agent (contractor) to perform a task. In addition to a common interest, the principal and the agent each have separate, individual interests. Asymmetric information benefiting the agent can create problems. It can even lead to moral hazard, if the agent's information advantage is so great as to eliminate any control by the principal.

This can be illustrated by the way in which port competition has changed with consequences for the investment and concession policies of the government and/or the port authority. The heterogeneous and complex structure of a sea port, with actors linked to each other within logistics chains, requires an in-depth knowledge at the disaggregated level of the decision processes of all the agents involved in the choice process. In addition to the competition between ports as a whole, competition also operates at the level of industrial companies and service providers. In this regard, competition has shifted from the level of individual ports to a competition between logistics chains. This results in several levels of competition, both horizontal and vertical, between actors, each having its own objectives and instruments (Meersman et al., 2010, pp. 217-219). The consequence is that, in addition to being dependent upon its own infrastructure and organisation, the competitive power of a port becomes a function of various internal and external market factors within that logistics chain.

Shippers and/or owners of goods may decide to carry out their own logistics operations, or they may outsource all or part of them. In the latter case, they are not directly involved in the choice of the shipping company, the terminal operating company, the hinterland transport provider or the port of origin or destination. A crucial question in this regard concerns which actor in the logistics chain will take which decision, with which consequences for the entire chain and the actors within it. Each actor has specific objectives and instruments for realising these objectives, and each actor can be both principal and agent. As a result the choice of a port thus becomes a simultaneous interactive process, and a function of several variables that are less and less controlled by the port authorities. In theory, the port belonging to the least expensive logistics chain should have the strongest competitive position.

The process of understanding and analysing the aforementioned decision processes has to deal with a dual challenge: to find relevant, reliable data and to have suitable model types. Data is often unavailable, incomplete or insufficiently reliable. Efforts could focus on alternative means of gathering information on changed transport flows. Recent examples include working with TAGs on containers or using GPS to follow lorry drivers. Track-and-trace systems in combination with sensors can already provide a large amount of information. These developments are creating databases that 
are large, electronic and continuously self-updating. This represents considerable progress, even if it does not yet provide any insight into how the actual decision process emerges. Further development of freight models will require access to micro-data.

It is not clear which types of models could be capable of representing these decision processes. Two model types emerge in this regard. One group consists of behavioural models, which proceed from the (random) utility function of the individual. Discrete choice models offer one example. In choice models, preferences and considerations (trade-offs) are derived from choice behaviour, and this information is subsequently used to predict future choices.

In addition, there are simulation models, in which reality is dynamically replicated. Proceeding from a given starting situation, a simulation generates developments over the time path in a controlled environment. However, simulations can lead to unreliable or even nonsense results if the model does not include a proper description of reality, if it is based on a faulty starting situation, if unrealistic assumptions have been made, or if uncertainties are neglected.

The most important point is that increasing attention should be devoted to the behaviour and reactions of all agents involved in freight transport, in order to estimate how they are likely to react to structural changes and policy measures. In addition to identifying the most important decisionmakers, this requires identifying smaller players, the market structures in which they are active and, most importantly, how they interact with each other. Research based on game theory investigating the corporate strategies of agents, market analysis and price-setting should be combined with models for optimising logistics chains and networks. Although considerable progress has already been made with regard to the various individual topics, it will be necessary to address the whole in order to improve the estimation of the influence of structural changes on freight transport. However, this can only be realised if there is access to micro-data and freight surveys.

\section{Consequences for the research agenda}

From a policy perspective it is important to have an idea of upcoming structural changes and the way in which they will affect freight transport. The majority of the existing freight models cannot cope with structural shifts because they often lack a rigorous treatment of the underlying fundamental behaviour of all the agents involved in freight transport. For some developments and problems, a technical-scientific solution could be found by constructing new model types and estimation methods. For other problems, a certain form of pragmatism will be necessary because for whatever reasons appropriate models cannot be designed (yet). Even if we do not know the exact behavioural patterns and reactions in the new working environment of the future, simulation models can be run under various scenarios to give at least an indication for policy design.

It is clear that structural shifts will influence the future research agenda in the area of modelling freight transport. For policy supporting models the focus should be on:

- New and/or adjusted models based on and reflecting the behaviour of all relevant agents. The choice of the methods and models should provide micro-economic explanations for the parameters of the relationships underlying the individual decision processes, in addition to 
offering an explanation for how individuals react to a changed policy environment (Boland, 2014, p. 43).

- Simulation models which help to analyse the possible impacts of different types of structural changes and their consequences for transport policy;

- New, better and relevant information because understanding and modelling the decisions of the individual agents in the logistics chain can only be achieved if highly disaggregated data are available.

Most choice models assume 'linear-additive utility maximisation' as a choice rule (in this regard, see e.g. Ben-Akiva and Lerman, 1985). In essence, this rule specifies that, in a set of choices, an actor will select the alternative with the greatest utility. It proceeds from the hypothesis that the utility associated with a specific alternative is exclusively dependent upon that alternative, and not on other or competing alternatives. In recent years, several developments have taken place in this regard as well. One example concerns the 'random regret minimisation model', in which decisionmakers attempt to avoid regret when making choices (Chorus, 2014, p. 9). This model is based on the hypothesis that the performance of the options that are not retained effectively influence the option that is chosen. Most choice models for freight transport continue to assume preferences that do not change. By drawing upon the knowledge of neuroscientists, however, we can gain insight into how these preferences emerge, why they might change and how they can be influenced. This could help to enhance understanding concerning choices that are made.

Freight transport is driven by decisions throughout the entire supply chain. Production processes, inventory holding strategies, integration of and collaboration between chain members are some of the elements which will steer and manage freight transport flows. At a micro-level these processes need to be modelled in order to understand and quantify the impact of structural changes and transport policies on the freight flows. There have been some attempts to integrate the supply or the logistics chain in freight models (see amongst others: Tavasszy, Ruijgrok, and Davydenko, 2012; Ben-Akiva and de Jong, 2013; Flitsch and Brümmerstedt , 2015)

Simulation is often essential when the model is very complex with many variables and interacting agents for which the underlying relationships are nonlinear. Simulation models could be derived from the broad array of currently available model types: proceeding from simulation models that replicate reality as accurately as possible, while also estimating the consequences of policy measures and/or unexpected events. They can be used for analyses within a specified period, as well as for purposes of making future projections. We could opt for causal deterministic simulations or for stochastic simulations based on drawings from a given probability distribution. It is possible to depart from the rather theoretical simulation and introduce experimental elements (e.g. by explicitly considering the decisions and reaction patterns of actors).

Recently, model-building and the empirical applications have been able to draw upon more data sources and data types than ever before although detailed commercially sensitive data is still hard to get. Future research will require simultaneous efforts: models aimed at the new data that can be used and data collection set up for the purpose of feeding into these new models.

The model types that can be retained for estimating the effects of structural shifts on the freight transport system will have their own specific evolutions. A good example is the further incorporation 
of behavioural mechanisms (behavioural realism) in choice models, possibly by including such variables as altruism, fairness and social responsibility (Chorus, 2014, p. 11).

The combination of models and big data also poses important challenges. For example, the choice models that are currently in use draw on highly refined and detailed data, even though most of the big-data sets that are currently available are often not sufficiently detailed to estimate some of the crucial parameters. Chorus $(2014$, p. 14) regards this as one of the most important directions for future research, writing that 'This mismatch triggers a fundamental rethink of choice models and the data they consume'

\section{Conclusions}

Policy makers have always, but not necessarily with the same intensity, called on transport models to support their policy. This has led to waves of different transport models targeted at the specific issues at stake. The evolution in freight transport models has in general lagged behind the developments in passenger transport models largely due to the lack or non-disclosure of reliable and detailed data. In addition where in passenger transport choices are in general made by the person who wants to travel, in freight transport often a number of agents are involved in the decision process of shipping goods from origin to destination. The complexity of this process was only occasionally explicitly incorporated in the existing freight models. As a consequence the majority of these models is not sufficiently robust for a fast and drastically changing environment.

In order to be able to cope with structural shifts much more attention should go to modelling or simulating the behaviour of all the decision makers along the logistics and even the supply chain. This process has already started as we see some efforts to incorporate the logistics decisions into traditional four-step freight models using data that have thus far been unavailable. This combination of existing model types which are undergoing continuous development with big-data sets and detailed freight surveys will make it possible to arrive at a better understanding of what is actually taking place in areas for which some traditional models are no longer usable. In a subsequent phase, this will also allow us to arrive at better-founded projections of future transport flows and strategies. In this regard, we should always keep the following quotation in mind (Boland, 2014, p. 144, with reference to personal correspondence with Hendry): 'The key issue is unknown unknowns, specifically unanticipated shifts in the underlying processes that were not pre-modelled'.

\section{References}

Ben-Akiva, M. and Lerman S. R. (1985) Discrete Choice Analysis. Theory and Application to Travel Demand, The MIT Press, Cambridge, Massachusetts.

Ben-Akiva, M., Meersman, H., and Van de Voorde, E. (eds) (2013) Freight Transport Modelling, Emerald Group Publishing Limited, Bingley.

Ben-Akiva, M., and de Jong, G., (2013), 'The Aggregate-Disaggregate-Aggregate (ADA) Freight Model System', in Ben-Akiva, M., Meersman, H., and Van de Voorde, E. (eds) Freight Transport Modelling, Emerald Group Publishing Limited, Bingley, pp.69-90 
Boland, L. A. (2014) Model building in economics: its purposes and limitations. Cambridge University Press, New York.

Chorus, C. (2014) Turning the light on in Virginia: new perspectives on choice behavior modeling, Public lecture, Institutional Repository, Delft University of Technology.

EEA, Eurostat (2016) "Greenhouse gas emission statistics" available at: http://ec.europa.eu/eurostat/statistics-explained/index.php/Greenhouse_gas_emission_statistics (accessed 5 March 2017)

Flitsch, V. and Brümmerstedt, K. (2015) 'Freight Transport Modelling of Container Hinterland Supply Chains' in Blecker, T., Kersten, W. and Ringle, C.M. (eds) Operational Excellence in Logistics and Supply Chains. epubli GmbH, ISBN (online): 978-3-7375-4058-2, ISBN (print): 978-3-7375-4056-8; ISSN (online): 2365-5070, ISSN (print): 2635-4430

IPCC (2014) Climate Change 2014: Mitigation of Climate Change. Contribution of Working Group III to the Fifth Assessment. Report of the Intergovernmental Panel on Climate Change [Edenhofer, O., R. Pichs-Madruga, Y. Sokona, E. Farahani, S. Kadner, K.]

Lucas, R.E., Jr. (1976) 'Econometric policy evaluation: a critique' in Brunner, K. and Meltzer, A. (eds), The Phillips Curve and the Labor Market, Vol. 1 of Carnegie-Rochester Conference on Public Policy. Amsterdam, North-Holland Meersman, H., Van de Voorde, E., and Vanelslander, T. (2010) 'Port Competition Revisited', Review of Business and Economics, 55(2), pp. 210-232.

Tavasszy, L.A., Ruijgrok, K., and Davydenko, I. (2012) 'Incorporating Logistics in Freight Transport Demand Models: State-of-the-Art and Research Opportunities'. Transport reviews, 32 (2), 203-219 